\title{
Irritable bowel-type symptoms in spontaneous and induced constipation
}

\author{
S N MARCUS AND K W HEATON \\ From the University Department of Medicine, Bristol Royal Infirmary, Bristol
}

SUMMARY The prevalence and severity of irritable bowel symptoms was assessed by systematic questioning in 44 constipated volunteers, most of whom had documented slow intestinal transit. All but two had one or more of the following: passage of mucus, rectal dissatisfaction, bloating, and abdominal pain relieved by defecation. All the symptoms were more prevalent than in 17 normal volunteers or in 301 apparently healthy people studied previously. When 12 normal subjects were made constipated with loperamide all developed one or more irritable bowel symptoms. When 24 constipated subjects received effective laxative treatment the prevalence and severity of these symptoms fell markedly. The findings suggest that in some subjects the slowing down of intestinal transit is associated with irritable bowel symptoms.

Descriptions of constipation are generally confined to the size and consistency of the stools and the frequency and effort of passing them. Text books of gastroenterology have separate sections on constipation and the irritable bowel syndrome, implying that they are distinct conditions with different symptomatologies. ${ }^{12}$ One monograph on functional gut disorders does give an account of constipation as one of the 'syndromes of the irritable gut' ${ }^{3}$ but another gives constipation only a passing mention, ${ }^{4}$ and a third discusses the mechanisms and pathophysiology of constipation but not its symptoms. ${ }^{5}$

There is no generally agreed definition of constipation. Some people have difficulty with defecation despite a normal transit time through the colon. Slow transit, however, is generally accepted as objective proof of constipation. To our knowledge there has been no systematic attempt to record the symptoms in people with confirmed slow transit constipation, spontaneous or induced, nor to observe how these symptoms change when the constipation is effectively treated. We have been able to examine these points in a group of normal volunteers who allowed themselves to be made constipated as part of a study on the role of intestinal transit in the aetiology of gall stones ${ }^{6}$ and also in a large group of subjects with spontaneous constipation who volunteered for the same study or

Address for correspondence: Dr K W Heaton, Department of Medicine. Bristol Royal Infirmary, Bristol, BS2 8W.

Received for publication 8 May 1986 for a parallel one on the effects of a new, concentrated wheat fibre preparation, ${ }^{7}$ both of which involved effective treatment of the constipation.

\section{Methods}

SUBJECTS AND DESIGN OF STUDY

As part of an investigation into the interrelationships between bowel transit time, bile acid metabolism and the risk of gall stones, ${ }^{6} 61$ subjects were recruited by means of posters in local chemist shops, health centres, hospital waiting areas, and WRVS stalls, and by advertisements in university and health authority circulars. The advertisements in the circulars called for volunteers irrespective of their bowel function. The posters read as follows: 'Attention all constipation sufferers. Please help us to help you. The University Department of Medicine is doing research into constipation and is in great need of volunteers willing to have a few safe and simple tests. We would provide treatment for your constipation at the same time. If you are aged about $45-65$ years and might be interested in helping us, please ring Bristol Royal Infirmary (Tel 22041) and ask to speak to Dr S Marcus who will be happy to give you further details without any obligation.' When would-be volunteers telephoned in response to the posters they were asked the nature of their problem. Only those stating that their problem was longstanding constipation were interviewed further. If they spontaneously mentioned abdominal pain or if, in this initial tele- 
phone call, they admitted to episodic symptoms and, especially, to episodes of diarrhoea, they were excluded from the study. None of the volunteers accepted into the study had sought medical aid for abdominal symptoms. Other criteria for exclusion were general ill health of any sort and unwillingness to consider having duodenal intubation or the administration of radioactivity because these were integral to the main study reported elsewhere. ${ }^{67}$

When they attended the hospital, subjects were taken through a detailed questionnaire about bowel function, and all but 11 subjects underwent measurement of whole gut transit time by a modified version ${ }^{6}$ of the single stool method.$^{8}$ Forty four volunteers (eight men and 36 women aged 36-69 years, mean 50 years) were classified as constipated. They admitted to three bowel actions per week or less and to frequent straining to pass scybalous faeces, and their transit time (measured in all but eight subjects) averaged $131 \mathrm{~h}$ (range 68-264). These subjects had been constipated for between $1 \frac{1 / 2}{2}$ and 55 years. Seventeen volunteers (three men and 14 women aged 38-63 years, mean 48 years) had a normal bowel habit and their transit time (measured in all but three subjects) averaged $47 \mathrm{~h}$ (range 29-64).

Of the 44 constipated subjects, 16 were not studied further. The remaining 28 were randomised into two groups. The first consisted of two men and 12 women aged 38-69 years (mean 48), who were prescribed sennoside-B (Senokot) tablets in a single daily dose sufficient to relieve their constipation $(15-60 \mathrm{mg}$ daily) for six weeks. Relief of constipation was defined as the passage of soft stools without straining on, at least, alternate days. The dose of Sennoside-B and its effect were monitored by one of us (SNM) with regular telephone calls. At the end of these six weeks, transit time was measured and the questionnaire was administered again to 12 subjects, that is, to all but the first two who were overlooked. The second group consisted of two men and 12 women aged 34-63 years (mean 51) who were prescribed sachets of a concentrated wheat fibre preparation, Testa Triticum Tricum (Trifyba, Labaz), containing $80 \%$ dietary fibre by weight, and were instructed to take them with meals in a dose sufficient to relieve their constipation (10-32 g daily) for six weeks, the effect again being monitored by regular telephone calls. At the end of this period, transit time was measured and the questionnaire was administered again to 12 of the subjects, that is, to all but the first two. One of the subjects given Testa Triticum Tricum was restudied after taking senna laxative for a second experimental period, while six of the subjects initially prescribed senna laxative were restudied after Testa Triticum Tricum. In these seven subjects, the second treatment period was extended to 12 weeks in lieu of a treatment free washout period, to which the subjects would not agree.

There was no significant difference in symptom scores between those constipated volunteers who were randomised into the two treatment groups and those who were not. Consequently all 44 spontaneously constipated volunteers were pooled when appropriate.

Of the 17 volunteers with normal bowel function, three were not studied further. The remaining subjects, two men and 12 women aged 38-62 years (mean 42), were prescribed loperamide capsules and instructed to take them in divided doses sufficient to reduce the frequency of defecation and induce straining at stool. The required dosage was $4-8 \mathrm{mg}$ in 10 subjects, $2 \mathrm{mg}$ in one and $20 \mathrm{mg}$ in one. The capsules were taken for six weeks, again with telephone monitoring. Transit time was then measured and the questionnaire administered again to 12 subjects.

The questionnaire used was based on that used by Thompson and Heaton' in their study of the prevalence of functional gastrointestinal symptoms. It was always administered by the same person (SNM) with explanations when necessary. The questions dealt with symptoms which, in patients without pointers to organic disease, are useful in diagnosing the irritable bowel syndrome, namely, passage of mucus, rectal dissatisfaction (sensation of incomplete evacuation of faeces), bloating or abdominal distension, and colonic pain. " Colonic pain was defined as abdominal pain relieved or improved by a bowel action. With each symptom, subjects were asked how often it occurred.

Symptoms except colonic pain were scored as follows: four points when the symptom occurred every day or at every defecation, three points for most days or defecations, two points for half the occasions and one point for just occasionally. Because the frequency of colonic pain was not systematically assessed, pain was scored simply as one point when it had occurred on more than six occasions in the year before the study or when it occurred at all during the treatment period. Following Thompson and Heaton, ${ }^{9}$ symptoms were also categorised as occurring 'ever' and occurring 'often', that is, on half or more occasions.

The data were processed by computer to determine the frequency of each symptom and its severity before and after treatment, and to compare the prevalence of each symptom with that in 301 apparently healthy volunteers previously studied. ${ }^{9}$ The significance of change in symptoms was assessed by the Wilcoxon's matched-pairs signed-rank test. For comparison of symptoms between groups, the Wilcoxon's rank sum w-test was used. For comparing the prevalence of symptoms between normal and 
constipated subjects $\chi^{2}$ analysis was used. Changes in whole gut transit time were assessed by the paired $t$-test. Statistical significance was taken as $\mathrm{p}<0 \cdot 05$.

\section{Results}

Table 1 shows the prevalence of irritable bowel symptoms in the 44 spontaneously constipated subjects, also in the 17 normal subjects and in 301 apparently healthy volunteers, ${ }^{9}$ the last two groups being statistically indistinguishable. All four symptoms were significantly more prevalent in the constipated subjects than in the healthy volunteers and all except pain were more prevalent than in the normal subjects.

Table 2 shows the change in symptom scores and transit time in constipated subjects treated with senna laxative and Testa Triticum Tricum and in normal subjects made constipated with loperamide. With senna laxative there was a marked reduction in the passage of mucus, rectal dissatisfaction and

Table 1 Number and \% of subjects with irritable boweltype symptoms among 44 subjects with spontaneous constipation compared with 17 normal subjects and 301 apparently healthy volunteers

\begin{tabular}{|c|c|c|c|}
\hline Symptom & Group & $\begin{array}{l}\text { Symptom } \\
\text { 'ever' }\end{array}$ & $\begin{array}{l}\text { Symptom } \\
\text { 'often' }\end{array}$ \\
\hline \multirow[t]{3}{*}{ Mucus } & Constipated subjects & $27(61 \%)$ & $9(26 \%)$ \\
\hline & Normal subjects* & $2(12 \%)$ & $0(0 \%) \ddagger$ \\
\hline & Healthy volunteers $\dagger$ & $16(5 \%) \|$ & $6(2 \%) \rrbracket$ \\
\hline \multirow{3}{*}{$\begin{array}{l}\text { Rectal } \\
\text { dissatisfaction }\end{array}$} & Constipated subjects & $36(82 \%)$ & $17(39 \%)$ \\
\hline & Normal subjects* & $11(65 \%) \ddagger$ & $1(6 \%) \S$ \\
\hline & Healthy volunteers $\dagger$ & $149(50 \%) \emptyset$ & $30(10 \%) q$ \\
\hline \multirow[t]{3}{*}{ Colonic pain } & Constipated subjects & $13(30 \%)$ & - \\
\hline & Normal subjects* & $2(12 \%)$ & - \\
\hline & Healthy volunteers $\dagger$ & $41(14 \%) \S$ & - \\
\hline \multirow[t]{3}{*}{ Bloating } & Constipated subjects & $35(80 \%)$ & $17(39 \%)$ \\
\hline & Normal subjects* & $2(12 \%) \pi$ & $0(0 \%)$ \\
\hline & Healthy volunteers $\dagger$ & $90(30 \%) \pi$ & $28(10 \%)$ \\
\hline
\end{tabular}

*Present study; †Data from Thompson and Heaton $;$; $<<0.05$ $\S p<0 \cdot 02 ; \| p<0 \cdot 01 ; \Uparrow p<0.001$ compared with constipated subjects. bloating. The prevalence of colonic pain was unchanged. With Testa Triticum Tricum, there was a significant reduction in the passage of mucus and in rectal dissatisfaction and a trend towards reduced prevalence of colonic pain $(p<0 \cdot 07)$, but no improvement in bloating.

When constipation was induced with loperamide (Table 2), there was a significant increase in rectal dissatisfaction and abdominal bloating and the prevalence of colonic pain increased markedly. Passage of mucus was unchanged. When subjects with spontaneous constipation and with loperamide induced constipation were compared, there was no difference in rectal dissatisfaction, colonic pain or bloating. There was no difference in the prevalence of mucus occurring 'often' but its occurrence 'ever' was more prevalent in spontaneous constipation $(61 \%$ vs $17 \%$, $\mathrm{p}<0 \cdot 001$ ).

Taking all 56 subjects with spontaneous and induced constipation, five had all four of the irritable bowel symptoms, 29 had three symptoms, 14 had two symptoms, six had one, and only two had none at all. All 12 normal subjects made constipated with loperamide had one or more irritable bowel symptoms.

\section{Discussion}

This study has shown by systematic questioning that symptoms of the irritable bowel syndrome are much more common in people with confirmed constipation, that is with slow whole gut transit, than in the population at large, that these symptoms are largely alleviated by effective laxative treatment, whether by a chemical laxative or a fibre preparation, and that the same symptoms appear in most normal people when they are made constipated. Only a tiny minority of people with constipation, spontaneous or induced, escape one or more irritable bowel symptoms and most have three or four.

The fact that senna laxative made little difference to the prevalence of colonic pain is not surprising

Table 2 Sum of symptom scores and (in brackets) median score, also whole-gut transit-time, in constipated subjects before and after treatment with senna laxative or Testa Triticum Tricum and in healthy subjects made constipated with loperamide

\begin{tabular}{|c|c|c|c|c|c|c|}
\hline & \multicolumn{2}{|c|}{$\begin{array}{l}\text { Constipated subjects } \\
\text { given senna }(n=13)\end{array}$} & \multicolumn{2}{|c|}{$\begin{array}{l}\text { Constipated subjects given } \\
\text { Testa Triticum Tricum }(n=18)\end{array}$} & \multicolumn{2}{|c|}{$\begin{array}{l}\text { Normal subjects given } \\
\text { loperamide }(n=12)\end{array}$} \\
\hline & Before & After & Before & After & Before & After \\
\hline Mucus & $11(6)$ & $2(0) \ddagger$ & $13(1)$ & $2(0) \ddagger$ & $1(0)$ & $2(0)$ \\
\hline Rectal dissatisfaction & $18(1)$ & $4(0) \ddagger$ & $25(1)$ & $14(1)^{*}$ & $10(1)$ & $19(1) \dagger$ \\
\hline Colonic pain & $5(0)$ & $5(0)$ & $5(0)$ & $1(0)$ & $1(0)$ & $7(0)^{*}$ \\
\hline All 4 symptoms & $53(1)$ & $18(0) \S$ & $66(1)$ & $33(0) \S$ & $15(0)$ & $48(1) \ddagger$ \\
\hline Transit time (h) & $125 \pm 42$ & $54 \pm 35 \S$ & $121 \pm 34$ & $64 \pm 258$ & $48 \pm 11$ & $97 \pm 32 \S$ \\
\hline
\end{tabular}

${ }^{*} \mathrm{p}<0 \cdot 05 ; \mathrm{p}<0.02 ; \neq \mathrm{p}<0 \cdot 01 ; \S \mathrm{p}<0 \cdot 001$ compared with before treatment 
because it is well known that stimulant laxatives tend to induce colic. Similarly, the failure of the fibre preparation to remove the symptom of bloating is in keeping with the common experience that a high intake of fibre can induce distension and wind.

It is possible that the posters calling for volunteers with constipation attracted people with colonic symptoms more than symptomless people, in which case our subjects were unrepresentative of spontaneously constipated people in the community. The prevalence of irritable bowel symptoms was very similar, in our constipated volunteers however to 31 constipated subjects who were discovered previously in a community survey with a $96 \%$ response rate ${ }^{9}$ (colonic pain $30 \%$ and $26 \%$ respectively; bloating ever $77 \%$ and $58 \%$; bloating often $39 \%$ and $32 \%$; rectal dissatisfaction ever $82 \%$ and $77 \%$; often $41 \%$ and $39 \%$ ) except that passage of mucus was more prevalent in the present volunteers (ever $59 \%$ vs $16 \%$; often $18 \%$ vs $7 \%$ ). Furthermore, the prevalence of irritable bowel symptoms was statistically indistinguishable in the 44 subjects with spontaneous constipation and the 12 subjects with induced constipation, except for passage of mucus which was less common in the latter (perhaps because they had been constipated for only six weeks). The average score for all four symptoms was 4.0 in spontaneously constipated volunteers and 4.0 in normal volunteers taking loperamide.

The precise mechanism of irritable bowel symptoms is still unclear. ${ }^{511}$ At face value, the present findings strengthen the case for abnormal motility as the basis for pain, bloating, and rectal dissatisfaction, at least, in patients whose transit is slow. The alternative mechanisms - increased sensitivity of the bowel or increased awareness of it, however, are not ruled out. When colonic transit slows down there are changes in bacterial metabolism and in the absorption of bacterial metabolites ${ }^{612}$ and these metabolites could conceivably have effects on the local nerve plexuses in the colon or on the central nervous system.

The possibility that some of the symptom changes noted in this study were psychogenic and caused by suggestion must be considered. Our subjects with constipation may have expected to feel better in various ways when their constipation was treated by an interested doctor. In our frequent telephone conversations with the subjects, however, we did not discuss general symptoms but concentrated on stool characteristics and on the frequency and effort of defecation. Similarly, normal volunteers being made constipated with loperamide may have expected to feel unwell because of cultural influences but, again, in our interviews we said nothing to strengthen such an expectation. We doubt whether, nowadays, there is enough popular fear of constipation or even discussion about it to have engendered expectations of this kind. It is improbable that symptoms like rectal dissatisfaction and the passage of mucus are caused by fear or by cultural training. The most straightforward explanation of our data is that in some subjects the slowing down of intestinal transit is associated with the development of irritable boweltype symptoms.

We are indebted to Mr A Hughes, MSc for statistical help.

\section{Addendum}

Since this paper was submitted, D M Preston and J E Lennard-Jones have reported a high frequency of abdominal pain and bloating in women with severe idiopathic slow transit constipation (Gut 1986; 27: 41-8).

\section{References}

1 Sleisenger MH, Fordtran JS, eds. Gastrointestinal disease. 3rd ed. London: Saunders, 1983.

2 Bouchier IAD, Allan RN, Hodgson HJF, Keighley MRB, eds. Textbook of gastroenterology. London: Bailliere Tindall, 1984.

3 Thompson WG. The irritable gut; functional disorders of the alimentary canal. Baltimore: University Park Press, 1979.

4 Chey WY, ed. Functional disorders of the digestive tract. New York: Raven Press, 1983.

5 Read, NW, ed. Irritable bowel syndrome. London: Grune and Stratton, 1985.

6 Marcus SN, Heaton KW. Intestinal transit, deoxycholic acid and the cholesterol saturation of bile: three interrelated variables. Gut $1986 ; 27$ : 550-8.

7 Marcus SN, Heaton KW. Effects of a new concentrated wheat fibre preparation on intestinal transit, deoxycholic acid metabolism and the composition of bile. Gut 1986; 27: 893-900.

8 Cummings JH, Wiggins HS. Transit through the gut measured by analysis of a single stool. Gut 1976; 17: 219-23.

9 Thompson WG, Heaton KW. Functional bowel disorders in apparently healthy people. Gastroenterology 1980; 79: 283-8.

10 Manning AP, Thompson WG, Heaton KW, Morris AF. Towards positive diagnosis of the irritable bowel. $\mathrm{Br}$ Med J 1978; 2: 653-4.

11 Thompson WG. The irritable bowel: one disease, or several, or none? In: Read NW, ed. Irritable bowel syndrome. London: Grune and Stratton, 1985: 3-14.

12 Cummings JH, Hill MJ, Bone ES, Branch WJ, Jenkins DJA. The effect of meat protein and dietary fiber on colonic function and metabolism. II. Bacterial metabolites in feces and urine. Am J Clin Nutr 1979; 32: 2094-101. 